\title{
Construct-it: A board game to enhance built environment students' understanding of the property lifecycle
}

\section{Authors:}

\section{S. Hayhow}

Birmingham City University, UK

\section{E.A. Parn}

Birmingham City University, UK

\section{D.J. Edwards}

Birmingham City University, UK and University of Johannesburg, South Africa

\section{Reza Hosseini}

Deakin University, Australia

\section{Aigbavboa}

University of Johannesburg, South Africa

\section{Corresponding author:}

D.J. Edwards, Faculty of Environment, Technology and Engineering, Birmingham School of the Built Environment, Birmingham City University, City Centre Campus, Millennium Point, Birmingham B4 7XG, UK. Email: david.edwards@bcu.ac.uk

\begin{abstract}
:
This paper investigates the development of a board game entitled 'Construct-it' as an innovative pedagogical approach (as proof of concept) to augmenting the applied knowledge and understanding of built environment students studying property lifecycle analysis. A largely qualitative and inductive methodological approach is conducted to: identify and investigate the various pertinent theoretical frameworks that could be adopted; conduct a critical synthesis of extant literature; and develop Construct-it, a game intuitively grounded in practice-based knowledge. The study reveals that games provide a fun, engaging and challenging means of educating students at higher education institutions. It also notes a significant dearth of literature in terms of applying games to students enrolled on built environment programmes. Construct-it can
\end{abstract}


enhance the student's learning experience and knowledge of pertinent industry practice and standards, and can complement traditional classroom teaching approaches. The study concludes with directions for the future work required to enhance the development of the novel pedagogical proof of concept presented. Such work will require robust testing and validation of the game to measure its impact on the student learning experience.

\section{Keywords:}

Built environment students, educational games, Construct-it, innovative pedagogical approach

Play and games are considered to be fundamental aspects of human endeavour that are embedded in our society and culture (Roberts et al., 1959). They allow for suspension of reality and freedom from ordinary life (Callious, 1961; Huizinga, 1955). Due to their compelling nature, games have also been applied and utilized in various arenas of education as an innovative pedagogical approach to enhancing the knowledge and performance of students (Braghirolli et al., 2016). Games can be used to engender the creation of new learning environments by integrating thinking, social 'collaborative' interaction and technology (Kafai et al., 1998). This application of gameplay has been capitalized on by several educational sectors, including: health studies, to train students in, for example, the better diagnosis of patients (Gibson and Douglas, 2013); business studies, to simulate real-life business environments (Hale et al., 2002); taxation for accounting purposes (Viviers, 2016); change management (Rajeev and Kalpathi, 2016); and military training, using strategy to simulate the success or otherwise of tactics employed - with the oldest (and still popular) game being chess (Wylie, 2017). This depth of game application, throughout a diverse range of contextual settings, illustrates how popular games can be treated as vehicles for augmenting students' teaching and learning experience.

However, in the context of the built environment, games as a pedagogical approach have hitherto received scant academic attention, with few papers identified in the extant literature (Shanbari and Issa, 2018). The research presented here seeks to address this lack of attention through an investigative development of a board game to augment student learning in built environment undergraduate programmes. Specifically, the research product will focus on a conceptual educational game (as a proof of concept, entitled 'Construct-it') that will enhance students' understanding of their own and their peers' ability to comprehend and articulate the property lifecycle process. The 'research challenges' confronting this work are twofold: first, to develop an innovative method of using games for knowledge retention enhancement in the built 
environment, and, second, to ensure that the game content is suitably grounded in practice-based knowledge in order to captivate and educate students and practitioners alike. In realizing the research aims through the development of Construct-it, the objectives are to: i) provide students of the built environment with comprehensive exposure to the whole lifecycle of a building, distilled for brevity into a 12-week taught module that is augmented with competitive fun and gameplay; ii) provide a safe educational environment for students to develop and expand their tacit knowledge of the built environment professions without being exposed to the high risks confronting them in practice (e.g. premature termination of contract or serious health and safety breach); and iii) produce more knowledgeable and competent future generations of graduates who are highly employable and recognized by pertinent professional bodies.

\section{A BRIEF HISTORY OF BOARD GAME DEVELOPMENT}

A timeline of board game development (see Figure 1) reveals that games were a part of human life even before the advent of written language (Attia, 2016). The earliest games were very simple, usually entailing the use of dice or dice sticks, but over time they advanced to include boards, counters and playing pieces (Gascoigne, 2001; Attia, 2016). The emergence of more familiar board games began with 'The Landlord Game', released in 1903 by Elizabeth Magie, the purpose of which was to educate users about realty and taxation (Forsyth, 2017). This led to a proliferation of board games during the next 50 years until the rise of 'Pong' - the first twodimensional simulated ping-pong 'arcade video game' created in 1958 by Atari (Ana, 2017) which launched a move away from board-based games to computer-based video games. However, 1977 heralded the birth of 'Dungeon and Dragons', one of the first board-based role-play games (RPGs) (Ana, 2017) and 1995 saw the release of 'Settlers of Catan', currently one of the most popular board games and available in a variety of different formats (Freeman, 2012). Role-play board games represented a paradigm shift in games development because they enabled players to immerse themselves as characters in a fictitious setting (Yue et al., 2017). Against this backdrop of progressive development, the start of the 21 st century has witnessed a significant revival in traditional board games, and during 2010-2014 board games sales increased year on year by between $25 \%$ and $40 \%$ (Duffy (2014). This was partly due to a significant improvement in game design and the level of interactivity, which in turn have instigated a gaming culture conducive to the establishment of gaming cafes around the country (Cross, 2017).

<Insert Figure 1 about here> 
There is a variety of means by which games can be classified. For example, one method is to distinguish between mechanistic, rule-based modes of gameplay (Janssen et al., 2015) and experiential modes, in which the games have both physical and mental activities and are more emotionally immersive (Hainey, 2010). Another classification compares and contrasts competitive, cooperative and collaborative modes of play (Zagal et al., 2006). Competitive games are those in which players are opposed to each other and there is a clear win-lose outcome; for instance, games such as chess, Go and draughts (Jones, 2000). Conversely, cooperative games are those in which the players are not opposed but have a mixture of common and oppositional goals. In the game, players can hold discussions and choose to negotiate and reach common agreements to provide enforceable contracts beneficial to both parties (Nash, 1953). A classic cooperative game is 'The Prisoner's Dilemma', a game of hypothetical scenarios in which two rational players may elect not to cooperate (and to act in their own self-interest) even if cooperation is mutually beneficial (Dawkins, 1989). Collaborative games involve teams of players who may have different information and must share and organize what they have learnt; either everyone wins or everyone loses, and so the main challenge is to work together against the board for the benefit of the whole group (Marschak et al., 1972).

\section{DELINEATING THE IDIOSYNCRASY INHERENT IN BUILT ENVIRONMENT EDUCATION}

For students of the built environment, a key challenge is to understand the lifecycle process of a building as a whole, from conceptual design (start) to demolition (finish) (Frearson, 2015). This lifecycle for a typical building is usually up to 120 years depending on its use and the operations and maintenance works conducted (Donnelly, 2015). Each stage of a building's development in this lifecycle (design, construction, occupation and demolition) requires the involvement of various professional disciplines (Latham, 1994; Pelligra, 2018). For example, the design stage involves the client, architect, planner and building control officer whereas the construction stage involves the main contractor, sub-contractors and tradesmen (albeit other parties may be involved depending on the procurement route adopted) (Jarkas, 2017; RIBA, 2013). Built environment students must comprehend the discrete roles and responsibilities of these different professionals at each stage, as effective and efficient teamworking is a prerequisite for working in the construction industry (Collier et al., 1991, Wood, 1999). Figure 2 provides a visualization that demonstrates the complexity of the stages and professionals involved in the development lifecycle - implicitly 
emphasizing the diverse range of skills and knowledge that a built environment graduate must possess to secure a successful career in the sector.

<insert Figure 2 about here>

For traditional teaching practices (which tend to divide knowledge and its application into small and often discrete parts), the challenge is to provide students with an understanding of the wider context of the whole property lifecycle in a multidisciplinary manner (Lehtinen, 2000). In practice, construction projects have historically fostered a team-based approach to erecting buildings and infrastructure - consequently, it is essential that such an approach is simulated in undergraduate programmes (Wood 1999; Wu et al., 2008). Failure to do so will negatively impact on a student's vernacular skill and knowledge of the industry, preparedness to work in a multicollaborative team and employability potential (Cleary et al., 2006; Robles, 2012; Olawale, 2015).

From another perspective, built environment students must demonstrate a required level of competence to secure membership of pertinent, prominent and prestigious professional bodies such as the UK's Chartered Institute of Building (CIOB), Royal Institution of Chartered Surveyors (RICS), Chartered Institute of Architectural Technologists (CIAT) and Royal Town Planning Institute (RTPI). Membership of such recognized professional bodies is highly important in an industry that rewards and recognizes professionalism and the various pathways to continuous professional development that are an integral part of it. Each of those qualifying bodies operates competence-based examinations for qualifying membership, as summarized in Table 1 (CIAT, 2015; CIOB, n/d; RICS, 2017: RTPI, 2015).

<Insert Table 1 about here>

Notably, in all instances, professional/industrial competencies are key prerequisites for any qualifying assessment, thus demonstrating the reliance and importance of an education grounded in practice but augmented with theory.

\section{RESEARCH DESIGN: DEFINING A CONTEMPORARY PEDAGOGICAL APPROACH FOR BUILT ENVIRONMENT STUDENTS}

The research sought to define a suitable, contemporary pedagogical approach to the design and utilization of an innovative, educational board game (Construct-it) for enhancing the tuition of 
property lifecycle analysis to built environment students. An iterative two-phase process was employed: i) a literature review - in which an inductive methodological research approach was adopted (Gioia et al., 2012), using secondary data to identify, analyse and synthesize other research conducted as part of a primary study; and ii) game development - in which the authors' own extensive practice-based knowledge and experience (accrued over many years of working in industry and academia) was used to inform the board game's design. This two-phase approach ensured that an optimized balance of theory and practice informed the game development.

\section{Literature Review}

A three-stage literature review strategy was employed: 1) identify pertinent sources of literature; 2) implement the literature review using convenience sampling; and 3) use literature to provide a richer and deeper understanding of gaming literature. This strategy enabled a componential synthesis of the extant literature to be conducted and a cross-comparison of the theories identified in the review to be undertaken.

- Stage 1. Identify pertinent sources of literature - this stage sought to identify appropriate data and sources extracted from journal and professional practice databases. Once identified, a keyword search was conducted to pinpoint relevant journals and authors using databases such as Scopus and the Web of Science. Keywords used included 'games', 'education', 'student learning' and 'built environment'.

- Stage 2. Implement the literature review using convenience sampling - during this stage, convenience sampling was used to identify the papers listed by authors in their latest research as a means of broadening the literature review.

- Stage 3. Use literature to provide a richer and deeper understanding of gaming literature - the objectives of this stage were to: i) determine the types of educational games developed in the literature; ii) identify how these games were designed and the mechanisms used to enable the transference of knowledge to students; and iii) determine the key characteristics of these games and their links to relevant theory.

\section{Game Development}

Research conducted in the literature review was then used as a robust theoretical basis on which to develop a proof of concept for Construct-it. Equally important was to ensure that Construct-it was suitably infused and grounded in contemporary practice-based knowledge. The various 
lifecycle stages of a construction project and the professionals involved in each stage were therefore defined and delineated. In addition, the types of examination arrangements established by pertinent professional bodies were also elaborated.

\section{DECIPHERING THE BENEFITS OF GAMES}

Prensky (2001) identifies an extensive list of advantages to be derived from using games as a pedagogical approach. These include: providing a form of activity that is both enjoyable and engaging; creating a logical structure to learning through the development of rules; and providing opportunities for enhancing knowledge by creating outcomes and feedback. Although Prensky (ibid) is prominent in the field of games for education, literature is replete with examples of other applications of games and their concomitant benefits, including: play/intense involvement; goal achievement; motivation; interaction/activity; feedback/learning and problem-solving/creativity. These desirable learning attributes make games an attractive accompaniment to existing educational instruction because they have innate capacity to augment the students' learning experience. Table 2 provides a componential analysis that cross references the benefits of games against a random selection of extant literature (using a non-probability convenience sample) (Etikan et al., 2015). Convenience sampling was adopted as a common sampling technique to ensure that accessible literature resources could be readily collated to demonstrate the range and variety of benefits to be accrued by using games (Farahman and Asgar, 2012).

\section{<Insert Table 2 about here>}

\section{Theoretical Frameworks}

Given the problem contextualization, any proposed game development must be underpinned by robust educational theory (Jayakanthan, 2002; Pourabdollain et al., 2012). From the literature review undertaken, constructivism (Bryant and Bates, 2015) appeared to offer the best methodological approach for this research scenario (i.e. developing effective games to augment built environment graduate learning) - see Table 3. Constructivism is defined as: "the assumption that knowledge is constructed by learners as they attempt to make sense of their experiences. Learners therefore are not empty vessels waiting to be filled, but rather active organisms seeking meaning" (Driscoll, 1994, p 360 cited in Obikwelu and Read, 2012). Within constructivism, several pertinent theories on game development predominate, namely: social constructivism - the creation of knowledge through interaction with others (Hay, 2016); zone of proximal learning defining what a learner can achieve with, and without, help or support (Wass and Golding, 2014); 
and situated learning - how individuals acquire professional skills from undertaking an activity (Hou, 2015). Each of these theories must be infused within the gameplay to maximize students' learning experience and concomitant routes to knowledge acquisition.

\section{<Insert Table 3 about here>}

\section{A CONCEPTUAL MODEL FOR CONSTRUCT-IT}

In the proof of concept game for built environment students, a mixture of collaboration (to ensure social constructivism) and competition (to ensure zone of proximal learning) were combined to create situated learning within the game's dynamics. Equally important was to ensure that Construct-it was suitably infused and grounded in contemporary practice-based knowledge. Hence, professionally competent and trained peers from within the host higher education institution were invited to attend a series of three focus group discussions (as part of pilot work) that sought to refine and hone the proof of concept prior to presenting the game to students. In order, the first session sought to present the game to six colleagues and elicit constructive feedback on game development, in readiness for the second session round of reviews and constructive feedback - as part of a finer granulation of feedback in the consultation process. Final revisions and presentation of the final revised game were then presented in third session to ensure (as far as reasonably practicable) that all concerns and queries had been addressed. The number of colleagues in each session varied subject to other work commitments but typically a minimum of three colleagues attended each session.

\section{Game Design and Structure}

The conceptual model for Construct-it is a 'team game' that brings professional disciplines together in order to simulate a real-life, collaborative project environment. During the game, built environment undergraduate students or newly qualified practitioners are tested on their knowledge of the whole lifecycle of a residential development. Professional disciplines that can play include architectural technicians, building surveyors, construction managers and quantity surveyors, but future variants could include other disciplines.

The basic components are the game board, dice, play tokens and question cards. Key categories of a building's lifecycle, as specified by the Royal Institute of British Architects (RIBA), were used to create eight progressive game tiers (see Table 4) which are represented on the game board in a two-dimensional plan view, similar to that of the four-sided ancient pyramid of Djoser (see Figure 3a). Advancement through the tiers takes the players along a linear temporal 
path signifying the eight key stages of a residential development. Specifically, tier one (at the outside edge of the board) denotes the start of the development while tier eight (at the centre of the board) denotes the final stage of the project life. At each tier level, the players must correctly answer questions relating to the lifecycle activities undertaken within that tier. The questions are categorized into three levels of difficulty and may take the format of multiple choice, textual or textual supplemented with a picture (such as a building fault that the players should be able to identify) and the highest level of difficulty will require a full descriptive answer. The question cards are linked to the tiers by the use of specific colours and pertinent decals for each tier. Figure $3 \mathrm{~b}$ provides a sample Tier 2 (groundworks) category card that poses a question and provides a model answer to present the highest level of difficulty. Hence, the question card presented serves as an exemplar only. Other types of cards will be produced - for example: i) questions that present pictures that require student to explain a building fault; ii) binary questions that require selection of the right answer to a question or indicate which image presents best practice; and iii) multiple choice questions that allow students to select one or more correct answers from a range of options available. Developing a range of question types in this manner will help to stimulate cognitive processing and help maintain students' interest in the game play.

$<$ Insert Table 4, Figure 3a and $3 \mathrm{~b}$ about here>

Questions posed are based on contemporary construction practice and are designed to test the players' knowledge of best practice for construction, as well as their ability to identify reasons for construction defects during building occupation and maintenance (such as premature deterioration of brickwork). The question categories are also directly tied into the intended learning outcomes for the taught module or programme award being studied.

\section{Gameplay}

The game is designed to allow four groups of four students to compete against each other in a student-student modus operandi - student-tutor interaction is minimized as far as reasonably practicable and limited to answering questions about gameplay. The overall aim is to progress through the game tiers to the centre of the board; this is achieved by successfully completing questions, which allows passage through gateways located between the tiers (denoted in Figure 3a as a 'gate' icon). The first team to reach the centre of the board wins but the game can continue until second, third and final places are confirmed. Although the aim is to test knowledge retained about the property lifecycle, an element of chance and excitement is provided via a dice that players must roll to part-determine progression through the game. At the start of the game, each 
team places its playing token on a different gateway square on tier 1. Each team member then rolls the dice and the team with the highest cumulative score starts gameplay first, the secondhighest starts second and so forth. On a team's turn, it rolls the dice and moves its token along a tier's squares according to the number shown on the dice. When a team lands on a question square, the opposing teams select a category question card and put the corresponding question to the playing team. The level of question difficulty is an arbitrary choice until a team answers that particular level of difficulty - at which point other levels of difficulty must be posed. If the team answers the question correctly, it wins that category level of difficulty (and the question card) and once cards from all three levels of difficulty are won, the team can advance to the next tier through a gateway on the board. To progress, the team must roll the dice to show the exact number required to land on a gateway square (introducing another element of chance). If a team answers two corresponding category questions wrongly, it loses a category card and opponents can choose to remove a card at any level of difficulty from the losing team.

\section{Future Validation and Development}

The validation and refinement of Construct-it will require rigorous and robust field testing with built environment students during future trialling and testing stage of the game's development. There are a number of research methods that could be applied. Two examples are: i) participatory action research $(P A R)$, which can be broadly described as collective self-experimentation amongst participants, augmented by evidential reasoning (participation), fact-finding (action) and learning (research) (Pärn and Edwards, 2017); and ii) a community of practice (CoP), which represents an extensive 'multiple stakeholder' collaboration platform working collectively together to instil teamwork in working processes for the benefit of all team members (Pärn et al., 2017). Data and information from validation testing will enable new knowledge of the impact of gameplay to be derived and greater wisdom in the staff and student communities to be realized. Regardless of which approach will be pursued, it is envisaged that Construct-it will be presented to a panel of final-year students (using focus groups) and a three-session format will be employed to elicit qualitative student feedback on the game's functionality and enjoyability. Once any outstanding issues have been addressed, the game will then be used by second-year students to measure its effectiveness in improving students' knowledge. Two dichotomous cohorts of pseudo-randomly selected students will be classified: game users and a control sample of nonusers. Key areas of student knowledge of a building's lifecycle will then be delineated and used as a means of comparison between the two subject groups. The work will use a two sample t-test at a 95\% confidence level to compare and contrast the performance of students (against each key area 
of subject knowledge) in a simulated mock exam paper. However, due to significant ethical constraints, validation testing methods will require considerable thought and the university's approval - for example, if two dichotomous groups of students are created (one a control group and the other exposed to the gameplay), the benefits of gameplay may be statistically revealed but the process could seriously disadvantage students in the control group. Hence, the main consideration will be to devise a test that does not compromise students - perhaps implemented once term studies have been completed.

Future variations of Construct-it could: i) incorporate additional development scenarios and structures, such as infrastructure, factories or office buildings; ii) be adapted for further disciplines, such as architects and planners; and iii) include extra levels of question difficulty, adjusted to suit first-, second- or third-year undergraduates. Future development could also encompass a computerized version of Construct-it with full integration into a database and automated new version releases. Such advances could use Industry 4.0 processes, technologies and philosophies - for example the Internet of Things (IoT), cloud computing and cognitive computing - to automate the learning experience and the marking of student performance in the gameplay. Such an approach would inextricably link education, games and computerization in one cohesive development (see Figure 4). The palpable advantages of a software version could include: i) wider participation via licensed subscription usage in built environment schools globally (not only could the funds thus gained fuel further development, but an expanded network of built environment researchers would provide benefit by the additional contribution of their intellectual capability to further game enhancements); ii) automated scoring of the game and record keeping of gameplay data (such data and information could provide a big data repository that could allow further interrogation of possible trends inherent in the gameplay dataset, e.g. exposing positive correlations between high scores obtained and the speed of game completion compared to students' scores in class); and iii) intelligent analysis of gameplay to inform lecturing staff and also for feedback to students, providing guidance on which topics to revisit in selflearning. A plethora of other concomitant benefits could well be revealed once the game has been launched and further discoveries, research questions or hypotheses are generated.

<Insert Figure 4 about here>

\section{CONCLUSION}

The education of built environment students has far-reaching ramifications for society, the economy and the environment. Specifically, the built environment (including homes, offices and 
infrastructural tributaries (i.e. road, rail, ports and air) created by future generations of practising construction managers, quantity surveyors and other professionals must be fit to live and work in. Moreover, the environment must be increasingly developed in a sustainable manner and conscious decisions made about the use of scarce natural resources. Built environment graduates must be able to work together to resolve these Gordian knot type problems, while still delivering projects on cost, to time and to a desirable level of quality. Further education and higher education institutions must work collectively to ensure that the most appropriate practice-based education is provided so that an appropriate standard of professional development can be achieved.

In this paper, an innovative game entitled Construct-it was developed as a proof of concept. Such game development may augment the teaching process in built environment subjects by providing an entertaining way of learning. Games have been used in other educational sectors (such as the social sciences) and with considerable aplomb, and transference of knowledge and experience from these sectors may well expedite the development process. Further research is required to validate and test the game and also to experiment with gameplay and version control. This could be readily achieved using a participant action research design for a sample of firstyear undergraduates, with two groups being formed, one group using the game and a control group not using it. Coursework grades could be compared between the two groups using t-test statistics at a $95 \%$ confidence rate. Ultimately, the success or otherwise of the proposed game will be measured by tangible improvements in students' grades awarded, but only through further experimentation and gameplay will the metrics for such assessment be determined.

\section{REFERENCES}

Ana, T. (2017) The Timeline of Board Game History. Available via: https://boardgamegeek.com/blogpost/67680/timeline-board-game-history [Accessed: April 2018]

Annetta, L.A. (2010) The "I's" Have it: A Framework for Serious Educational Game Design, Review of General Psychology, Vol. 14, No. 2, p. 105. DOI: http://dx.doi.org/10.1037/a0018985

Attia, P. (2016) The Full History of Board Games, Available via: https://medium.com/swlh/thefull-history-of-board-games-5e622811ce89 [Accessed: April 2018]

Braghirolli, L.F., Ribeiro, J.L.D., Weise, A.D. and Pizzolato, M. (2016) Benefits of Educational Games as an Introductory Activity in Industrial Engineering Education, Computers in Human Behavior, Vol. 58, pp. 315-324. DOI: https://doi.org/10.1016/j.chb.2015.12.063 
Bryant, J. and Bates, A.J. (2015) Creating a Constructivist Online Instructional Environment, TechTrends, Vol. 59, No. 2, pp. 17-22. DOI: https://doi.org/10.1007/s11528-015-0834-1

British Go Association (n.d.) A Brief History of Go. Available via: https://www.britgo.org/intro/history [Accessed: April 2018]

CAIT (2015) Chartered Membership: Professional Standards Framework, London: CIAT.

CIOB (N/D) Routes to Chartered Membership. Available via: http://www.ciob.org/routes [Accessed: February 2018]

Caillois, R. (1961) Man, Play and Games. IL, USA: University of Illinois Press.

Cleary, M., Flynn, R. and Thomasson, S., 2006. Employability Skills: From Framework to Practice-An Introductory Guide for Trainers and Assessors. Adobe Digital Edition version.

Collier, A., Bacon, J., Burns, D. and Muir, T. (1991) Interdisciplinary Studies in the Built Environment. London: Council for National Academic Awards.

Cross, T. (2017) Welcome to the Golden Age of Board Games - Brought to you by the Internet, Financial Review, 26 Dec. Available via: http://www.afr.com/lifestyle/welcome-to-thegolden-age-of-board-games--brought-to-you-by-the-internet-20171219-h07a36 [Accessed: April 2018]

Csikszentmihalyi (1991) Flow The Psychology of Optimal Experience, New York: Harper Perennial.

Dawkins, R. (1989) The Selfish Gene. New York: Oxford University Press

De Freitas, S. (2006) Learning in Immersive Worlds, A Review of Game-based Learning, Bristol: JISC. Available via: http://www.jisc.ac.uk/media/documents/programmes/elearninginnovation/gamingreport_v 3.pdf, [Accessed: February 2018]

Donnelly, B (2015) The Life Expectancy of Buildings, Available via: http://brandondonnelly.com/post/128489870433/the-life-expectancy-of-buildings

[Accessed: January, 2018].

Duffy, O (2014) Board Games Golden Age: Social, Brilliant and Driven by the Internet, The Guardian, $25^{\text {th }} \quad$ Nov, Available via: https://www.theguardian.com/technology/2014/nov/25/board-games-internet-playstationxbox [Accessed: April 2018]

Etikan, I., Musa, S.A. and Alkassim, R.S. (2015) Comparison of Convenience Sampling and Purposive Sampling, American Journal of Theoretical and Applied Statistics, Vol. 5, No. 1, pp. 1-4. DOI: 10.11648/j.ajtas.20160501.11 
Farahman, F. and Asgar, M-H. (2012) Rethinking Convenience Sampling: Defining Quality Criteria, Theory and Practice in Language Studies, Vol. 2, No. 4, pp. 784-792. DOI: 10.4304/tpls.2.4.784-792.

Freeman, W. (2012) Why Board Games are Making a Comeback, The Guardian, 9 ${ }^{\text {th }}$ Dec. Available via: https://www.theguardian.com/lifeandstyle/2012/dec/09/board-gamescomeback-freeman [Accessed: April 2018]

Forsyth, T. (2017) Monopoly Game History, Landlords Game History. Available via: http://landlordsgame.info/ [Accessed: April 2018]

Frearson, A (2015) UK Architecture Schools Fail to Equip Students with Skills Needed for Practice, Available via: https://www.dezeen.com/2015/02/02/uk-architecture-schools-failequip-students-skills-riba-appointments/ [Accessed: January 2018]

Gascoigne, B. (2001) History of Sports and games. Available via: http://www.historyworld.net/wrldhis/PlainTextHistories.asp?groupid=2280\&HistoryID=a c02\&gtrack=pthc [Accessed: April 2018]

Gee, J.P. (2003) What Video Games have to Teach us About Learning and Literacy, Computers in Entertainment (CIE), Vol. 1, No. 1, pp. 20-20 DOI: 10.1145/950566.950595

Gee, J. P. (2008) Learning and Games. In K. Salen (Ed.) The Ecology of Games: Connecting Youth, Games, and Learning (pp. 21-40). Cambridge, MA: MIT Press.

Gibson, V. and Douglas, M (2013) Criticality: The Experience of Developing an Interactive Educational Tool Based on Board Games, Nurse Education Today, Vol 33, No. 12, pp. 1612-1616. DOI; https://doi.org/10.1016/j.nedt.2013.01.022

Gioia, D.A., Corley, K.G. and Hamilton, A.L. (2012) Seeking Qualitative Rigor in Inductive Research: Notes on the Gioia Methodology, Organisational Research Methods, Vol. 16, No. 1, pp. 15-31. DOI: https://doi.org/10.1177/1094428112452151

Hainey, T. (2010) Using Games-based Learning to Teach Requirements Collection and Analysis at Tertiary Education Level. Unpublished PhD Thesis, University of the West of Scotland.

Hale Feinstein, A., Mann, S. and Corsun, D.L. (2002) Charting the Experiential Territory: Clarifying Definitions and uses of Computer Simulation, Games, and Role Play, Journal of Management Development, Vol. 21, No. 10, pp. 732-744. DOI: https://doi.org/10.1016/j.nedt.2013.01.022

Hay, C. (2016) Good in a Crisis: The Ontological Institutionalism of Social Constructivism, New Political Economy, Vol. 21, No. 6, pp. 520-535, DOI: 10.1080/13563467.2016.1158800

Hou, H-T. (2015) Integrating Cluster and Sequential Analysis to Explore Learners' Flow and Behavioral Patterns in a Simulation Game with Situated-Learning Context for Science 
Courses: A Video-Based Process Exploration, Computers in Human Behaviour, Vol. 48, pp. 424-435. DOI: https://doi.org/10.1016/j.chb.2015.02.010

Huizinga, J. (1955) 1938 Homo Ludens: A Study of the Play Element in Culture, London: Angelico Press.

Janssen, M.A., Lindahl, T. and Murphy, J.J. (2015) Advancing the Understanding of Behavior in Social-ecological Systems: Results from Lab and Field Experiments. Ecology and Society, Vol. 20, No. 4, p. 34 DOI: http://dx.doi.org/10.5751/ES-08097-200434

Jarkas, A. M. (2017) Contractors' Perspective of Construction Project Complexity: Definitions, Principles, and Relevant Contributors, Journal of Professional Issues in Engineering Education and Practice, Vol. 143, No. 4. DOI: https://doi.org/10.1061/(ASCE)EI.1943$\underline{5541.0000337}$

Jayakanthan, R. (2002) Application of Computer Games in the Field of Education, The Electronic Library, Vol. 20, No. 2, pp. 98-102. DOI: https://doi.org/10.1108/02640470210697471

Jones, K. (2000) Non-predatory Games. The Games Journal, Available via: http://www.thegamesjournal.com/articles/Nonpredatory.shtml [Accessed: April 2018].

Kafai, Y.B., Franke, M.L., Ching, C.C. and Shih, J.C. (1998) Game Design as an Interactive Learning Environment for Fostering Students' and Teachers' Mathematical Inquiry, International Journal of Computers for Mathematical Learning, Vol. 3, No. 2, pp 149-184. DOI: https://doi.org/10.1023/A:100977790

Kafai, Y.B. and Burke, Q. (2015) Constructionist Gaming: Understanding the Benefits of Making Games for Learning, Educational Psychologist, Vol. 50, No. 4, pp. 313-334. DOI: https://doi.org/10.1080/00461520.2015.1124022

Kapp, K.M., (2012) The Gamification of Learning and Instruction: Game-based Methods and Strategies for Training and Education. London: John Wiley \& Sons.

Kaptelinin, V. and Cole, M. (1997) Individual and Collective Activities in Educational Computer Gameplaying. In Proceedings of the 2nd International Conference on Computer Support for Collaborative Learning (pp. 142-147). International Society of the Learning Sciences.

Kiili, K., Lainema, T., de Freitas, S. and Arnab, S. (2014) Flow Framework for Analyzing the Quality of Educational Games, Entertainment Computing, Vol. 5, No. 4, pp. 367-377.

Latham Report (1994) Constructing the Team: Joint Review of Procurement and Contractual Arrangements in the United Kingdom Construction Industry. Chair Sir M. Latham. HMSO, London. DOI: https://doi.org/10.1016/j.entcom.2014.08.002 
Lave, J. and Wenger, E. (1991) Situated Learning: Legitimate Peripheral Participation, Cambridge: Cambridge University Press.

Lave, J. and Wenger, E. (1998) Communities of Practice. Available via: http://valenciacollege.edu/faculty/development/tla/documents/CommunityofPractice.pdf [Accessed: February 2018].

Lehtinen, E. (2000) Information and Communication Technology in Education: Desires, Promises, and Obstacles. In Communications and Networking in Education (pp. 311-328). Boston, MA: Springer.

Marschak, J. and Radner, R. (1972) Economic Theory of Teams. New Haven, CT: Yale University Press.

Millmore, M. (1997) Discovering Egypt Website. Available via: https://discoveringegypt.com/ancient-egyptian-game-senet/ [Accessed: April 2018]

Nash, J. (1953) Two-person Cooperative Games. Econometrica: Journal of the Econometric Society, pp. 128-140. DOI: http://www.jstor.org/stable/1906951

Obikwelu, C. and Read, J.C. (2012) The Serious Game Constructivist Framework for Children's Learning, Procedia Computer Science, Vol. 15, pp. 32-37. DOI: https://doi.org/10.1016/j.procs.2012.10.055

Olawale, Y. (2015) The Employability Skills Provision within a Construction Project Management Degree Programme. Available Via: https://pdfs.semanticscholar.org/91e8/ac8539fa51362d5a0aaa82a9773da4b84399.pdf

[Accessed: March 2018]

Oblinger, D. (2006) Simulations, Games and Learning. Educause Learning Initiative, pp. 1-6. Available via: https://er.educause.edu/ /media/files/articles/2008/8/eli3004.pdf?la=en [Accessed: May, 2018].

Pärn, E. A. and Edwards, D. J. (2017) Conceptualising the FINDD API Plug-in: a Study of BIMFM Integration. Automation in Construction, 80, pp. 11-21. DOI:10.1016/j.autcon.2017.03.015

Pärn, E. A., Edwards, D. J. and Sing, M.C.P. (2017) The Building Information Modelling Trajectory in Facilities Management: A Review. Automation in Construction, 75, pp. 4555. DOI:10.1016/j.autcon.2016.12.003

Pelligra, (2018) Understanding the Construction Process, Available Via: https://www.pelligra.com/understanding-the-construction-process/ [Accessed: February 2018].

Piaget, J. (1936) Origins of Intelligence in the Child. London: Routledge \& Kegan Paul. 
Pourabdollahian, B., Taisch, M. and Kerga, E. (2012) Serious Games in Manufacturing Education: Evaluation of Learners' Engagement, Procedia Computer Science, Vol. 15, pp. 256-265. DOI: https://doi.org/10.1016/j.procs.2012.10.077

Prensky, M. (2001) Digital Game-based Learning, Available via: http://www.marcprensky.com/writing/Prensky\%20-\%20Digital\%20Game-

Based\%20Learning-Ch5.pdf [Accessed: February 2018].

Rajeev, P.R. and Kalpathi, S. (2016) Let's Play: The Use of Improv Games in Change Management Training - A Case Study, Industry and Higher Education, Vol. 30, No. 2, pp. 149-154. DOI: https://doi.org/10.5367/ihe.2016.0299

RIBA (2013) RIBA Plan of Works, Available via: https://www.ribaplanofwork.com/ [Accessed: January 2018].

RICS (2017) Assessment of Professional Competence, Candidate Guide, London: RICS.

Roberts, J.M., Arth, M.J. and Bush, R.R. (1959) Games in Culture. American $\begin{array}{lllll}\text { Anthropologist, Vol. } & 61, \quad \text { No. } \quad 4, \quad \text { pp. } & \text { 597-605. }\end{array}$ https://doi.org/10.1525/aa.1959.61.4.02a00050

Robles, M.M. (2012) Executive Perceptions of the Top 10 Soft Skills Needed in Today's Workplace. Business Communication Quarterly, Vol. 75, No. 4, pp. 453-465.. DOI: https://doi.org/10.1177/1080569912460400

RTPI, (2015) Assessment of Professional Competence (APC) Guidance, London: RTPI.

Ruggiero, D. (2015) The Effect of a Persuasive Social Impact Game on Affective Learning and Attitude, Computers in Human Behavior, Vol. 45, pp. 213-221. DOI: https://doi.org/10.1016/j.chb.2014.11.062

Shanbari, H. and Issa, R.R.A (2018) Use of Video Games to Enhance Construction Management Education, International Journal of Construction Management, DOI: $10.1080 / 15623599.2017 .1423166$

Van Eck, R. (2006) Digital Game-based Learning: It's not just the Digital Natives who are Restless, EDUCAUSE Review, Vol. 41, No. 2, p. 16.

Viviers, H.A. (2016) Qualitative Evaluation of the Design Variables of a Teaching Intervention to Expose Accounting Students to Pervasive Skills, Industry and Higher Education, Vol. 30, No. 6, pp. 402-412. DOI: https://doi.org/10.1177/0950422216664244

Vygotsky, L.S. (1933) Mind in Society, The Development of Higher Psychological Processes, Cambridge, MA: Harvard University Press

Vygotsky, L.S, (1987) Zone of Proximal Development, Mind in Society: The Development of Higher Psychological Processes, Vol. 5291, p. 157. 
Wass, R. and Golding, C. (2014) Sharpening a Tool for Teaching: the Zone of Proximal Development, Teaching in Higher Education, Vol. 19, No. 6, pp. 671-684, DOI: $10.1080 / 13562517.2014 .901958$

Westera, W. (2017) How People Learn While Playing Serious Games: A Computational Modelling Approach, Journal of Computational Science, Vol. 18, pp. 32-45. DOI: https://doi.org/10.1016/j.jocs.2016.12.002

Wood, G. (1999) Interdisciplinary Working in Built Environment Education, Education + Training, Vol. 41, No. 8, pp. 373-380, DOI: https://doi.org/10.1108/00400919910298648

Wouters, P., van Nimwegen, C., van Oostendorp, H. and van der Spek, E. D. (2013) A MetaAnalysis of the Cognitive and Motivational Effects of Serious Games. Journal of Educational Psychology, Vol. 105, No. 2, pp. 249-265. DOI: http://dx.doi.org/10.1037/a0031311

Wu, S, Greenwood, D and Steel, G (2008) Exploring the Attributes of Collaborative Working in Construction Industry. Northumbria Working Paper Series: Interdisciplinary Studies in the Built and Virtual Environment, Vol. 1, No. 2, pp. 135-147. ISSN 1756-2473

Wylie, J.C. (2017) Military Strategy: A General Theory of Power Control, Annapolis, Maryland, USA: Naval Institute Press. ISBN: 978-1-61251-515-1.

Yue, S, Kim, E. and Lee, D. (2017) Exploring Avatar Identification in Game Addiction Among Massively Multiplayer Online Role-Playing Games (MMORPG) Players, Games and Culture, Vol. 12, No. 1, pp. 56-71. DOI: https://doi.org/10.1177/1555412015581087

Zagal, J.P., Rick, J. and Hsi, I. (2006) Collaborative Games: Lessons Learned from Board Games. Simulation \& Gaming, Vol. 37, No. 1, pp. 24-40. DOI: https://doi.org/10.1177/1046878105282279 
5000 BC - 49 carved and painted stones (a form of dice) from this period found in Turkey.

3000 BC - Mehen, dating from this period, found in Egypt. The board is formed as a serpent representing the snake-god Mehen with marbles, dice and lion-shaped pieces used for gameplay. $G o$ is also thought to have originated in China around this time (British Go Association, n.d.)

2000 BC - Backgammon-type game from the Roman empire.

400 BC - Liubo was the first Asian game not to follow Middle Eastern templates. Two players use six throwing sticks to determine the movement of six game pieces around a board.

700 AD - Mancala, earliest examples found in Eritrea and Ethiopia. This is a two-player strategy game that involves moving pieces along the board whilst capturing your opponent's pieces.

1500 AD - Draughts is first recorded in a Spanish book in 1547, although the game is likely to be older.

$1995 \mathrm{AD}$ - The Settlers of Catan is one of a series of modern multiplayer board games that are now part of popular culture. Players take on the roles of settlers, competing and trading to conquer Catan. (Duffy, 2014; Freeman, 2012)
3100 BC - Senet (game of passing) dating from this period found in Egypt. One of the earliest board games, played on a rectangular grid of 30 squares (three rows of 10) with two sets of pawns.

$2650 \mathrm{BC}$ - The Royal Game of $U r$ from ancient Mesopotamia (Iraq). The board consists of 20 squares and the game is played with sets of black and white counters and tetrahedral dice.

(Milmore, n.d.)

1300 BC - Ludus latrunculorum from the Roman Empire: a two-player game of military strategy and probably a forerunner of chess.

$400 \mathrm{AD}$ - Tafl (strategy board games) from Germanic and Celtic cultures. Two sets of unevenly numbered pieces are opposed: the king in the smaller set must escape from the centre of the board to the edge. An adapted version from India (Chaturanga) in the 6th or 7th century AD arrived in Europe as an early form of Chess.

900 AD onwards - Domino-type games (from carved ivory, wood and bone) and playing cards (paper-based). Originated in China.

1903 AD - The Landlord's Game from the USA: this became the modern-day Monopoly.

Figure 1. A timeline of board game development. 
Source: Adapted from Attia, 2016 and Gascoigne, 2001. 
Figure 2 - The stages and associated professionals within a property development lifecycle

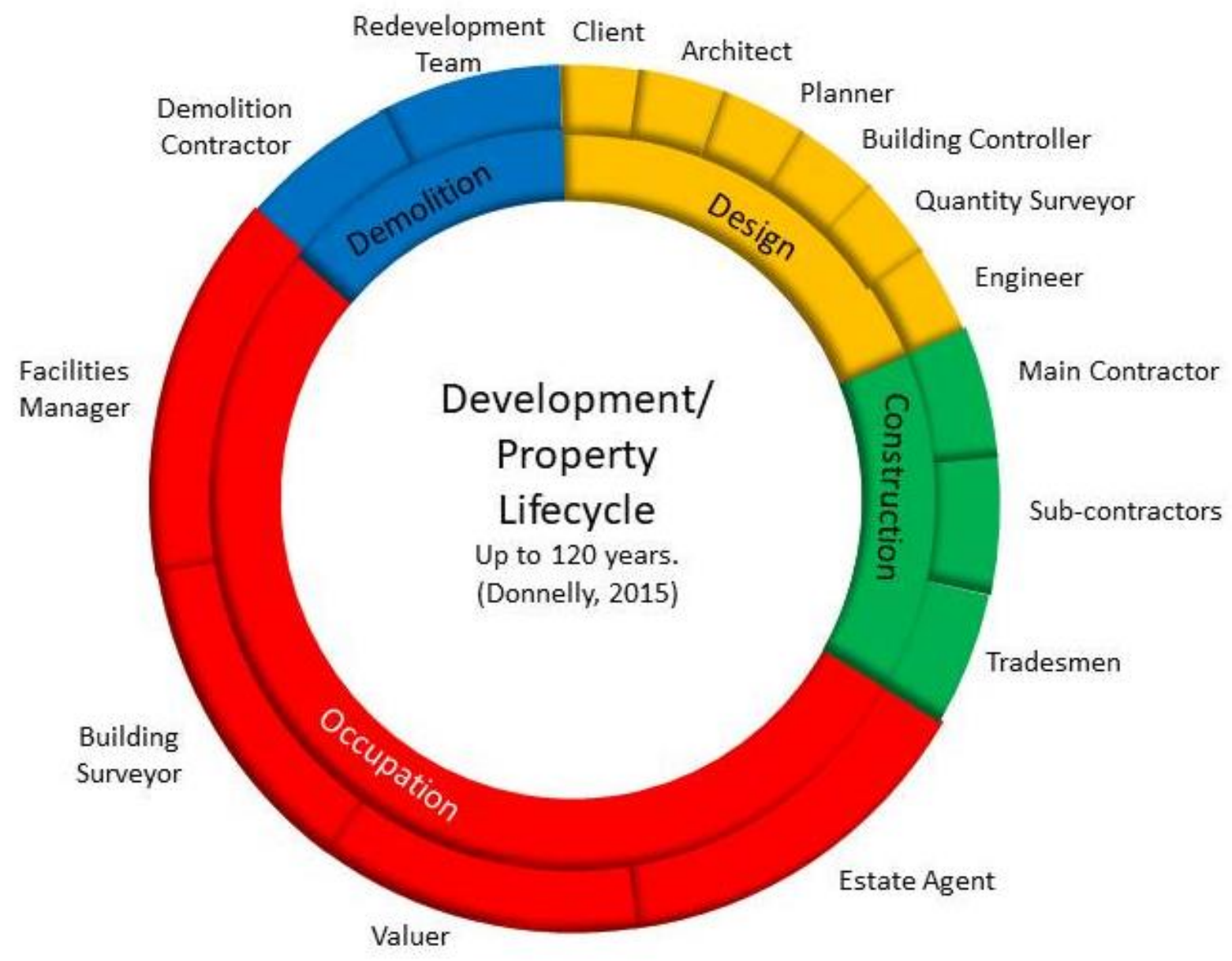


Table 1. Built environment professional body qualifying examinations in the UK.

\begin{tabular}{|c|c|c|}
\hline Institute & Description & Reference \\
\hline $\begin{array}{l}\text { Chartered Institute } \\
\text { of Building (CIOB) }\end{array}$ & $\begin{array}{l}\text { Complete and submit a summary of } \\
\text { experience covering mandatory and } \\
\text { technical competencies, submit a case study } \\
\text { and undertake a 1-hour interview. }\end{array}$ & RICS (2017) \\
\hline $\begin{array}{l}\text { Chartered Institute } \\
\text { of Architectural } \\
\text { Technologists } \\
\text { (CIAT) }\end{array}$ & $\begin{array}{l}\text { Complete a critical analysis covering } 4 \\
\text { competencies and undertake a } 40 \text {-minute } \\
\text { interview. }\end{array}$ & CIAT (2015) \\
\hline $\begin{array}{l}\text { Royal Institution of } \\
\text { Chartered Surveyors } \\
\text { (RICS) }\end{array}$ & $\begin{array}{l}\text { Assemble a portfolio of work to meet key } \\
\text { competencies across } 12 \text { units. }\end{array}$ & $\mathrm{CIOB}(\mathrm{N} / \mathrm{D})$ \\
\hline $\begin{array}{l}\text { Royal Town } \\
\text { Planning Institute } \\
\text { (RTPI) }\end{array}$ & $\begin{array}{l}\text { Complete a practical experience statement, } \\
\text { professional competence statement covering } \\
11 \text { competencies and a professional } \\
\text { development plan. }\end{array}$ & RTPI (2015) \\
\hline
\end{tabular}


Table 2. Componential analysis of extant literature.

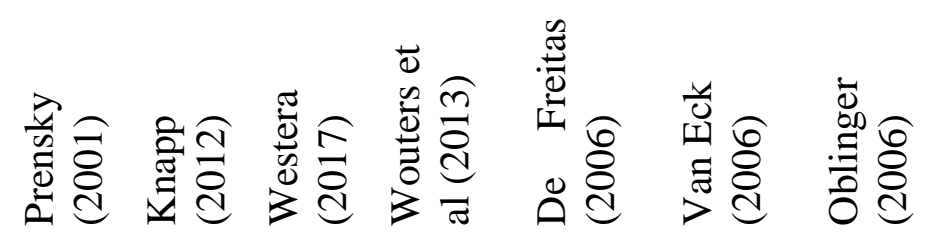

\section{Game benefits}

Fun/enjoyment

Play/intense involvement

Rules/structure

Goals/motivation

Interaction/activity

Adaption/flow

Outcomes and feedback/learning

Win states/gratification

Conflict/competition/ opposition

Problem solving/creativity

Interaction/social groups

Representation and story/emotion

Retention

Safe experimentation

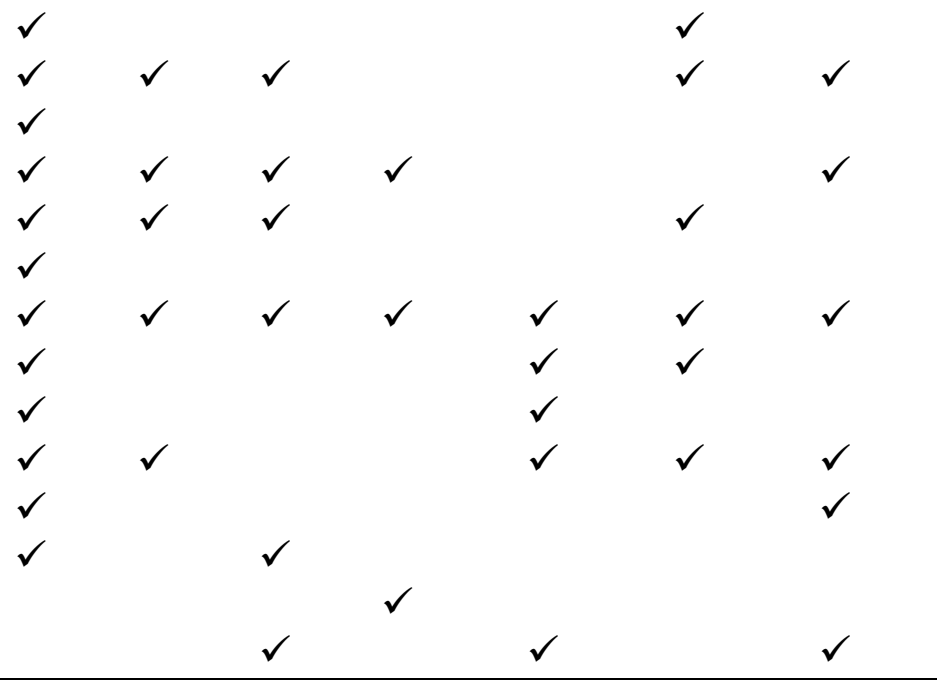


Table 3 . Theoretical frameworks.

\begin{tabular}{|c|c|c|c|}
\hline Frameworks & Theories & References & $\begin{array}{l}\text { Supporting } \\
\text { literature } \\
\text { for games }\end{array}$ \\
\hline \multirow{5}{*}{ Constructivism } & $\begin{array}{l}\text { Cognitive development: theory of how a } \\
\text { person constructs knowledge from their } \\
\text { experience and environment. }\end{array}$ & Piaget (1936) & $\begin{array}{l}\text { Van Eck } \\
(2006) \\
\text { Kafai et al } \\
(2015)\end{array}$ \\
\hline & $\begin{array}{l}\text { Social constructivism: social interaction } \\
\text { is necessary for the development of } \\
\text { cognition. }\end{array}$ & Vygotsky (1933) & $\begin{array}{l}\text { Annetta } \\
(2010)\end{array}$ \\
\hline & $\begin{array}{l}\text { Zone of proximal development: } \\
\text { difference between the abilities of a } \\
\text { student learning unaided compared to } \\
\text { being aided by a teacher with a higher } \\
\text { skill set. }\end{array}$ & Vygotsky (1978) & $\begin{array}{l}\text { Kaptelinin et } \\
\text { al (1997) } \\
\text { Killi et al } \\
\text { (2014) }\end{array}$ \\
\hline & $\begin{array}{l}\text { Situated learning: learning occurs } \\
\text { through active participation in an } \\
\text { activity that sets the context for the } \\
\text { learning. }\end{array}$ & Lave (1991) & $\begin{array}{l}\text { Gee (2008) } \\
\text { Kafai et al } \\
(2015)\end{array}$ \\
\hline & $\begin{array}{l}\text { Communities of practice: learning } \\
\text { develops through interaction with } \\
\text { people who have a similar goal. }\end{array}$ & $\begin{array}{l}\text { Lave and Wenger } \\
\text { (1998) }\end{array}$ & $\begin{array}{l}\text { Kafai et al } \\
(2015) \\
\text { Gee (2003) }\end{array}$ \\
\hline Humanism & $\begin{array}{l}\text { Flow: a mental state of being fully } \\
\text { immersed in an activity, where there is } \\
\text { complete focus, involvement and } \\
\text { enjoyment. }\end{array}$ & $\begin{array}{l}\text { Csikszentmilhályi } \\
\text { (1991) }\end{array}$ & $\begin{array}{l}\text { Killi et al } \\
(2014) \\
\text { Ruggiero } \\
(2015)\end{array}$ \\
\hline
\end{tabular}


Table 4 - Game tiers allocated to the categories of a building's lifecycle

\begin{tabular}{|c|c|c|}
\hline \multicolumn{2}{|c|}{ Tiers } & Categories \\
\hline \multirow[t]{2}{*}{1} & Pre-contract & Roles of stakeholders \\
\hline & & Legal considerations (contracts) \\
\hline \multirow[t]{5}{*}{2} & Groundworks & Setting out \\
\hline & & Excavation works \\
\hline & & Foundation concrete and rebar \\
\hline & & Brickwork/ blockwork to damp \\
\hline & & $\begin{array}{l}\text { proof membrane and foul/ storm } \\
\text { water drainage }\end{array}$ \\
\hline \multirow[t]{4}{*}{3} & External envelope to wall-plate & External brickwork façade \\
\hline & & Internal blockwork \\
\hline & & First floor joists \\
\hline & & External windows and doors \\
\hline \multirow[t]{7}{*}{4} & Roof and first fix & Trusses \\
\hline & & Felt and lathing \\
\hline & & Tiles and leadwork \\
\hline & & Electrical cables \\
\hline & & Plumbing and heating pipes \\
\hline & & Telecommunications cables \\
\hline & & Doorframes \\
\hline \multirow[t]{4}{*}{5} & Second fix and finishes & Brown and skim plasterwork \\
\hline & & $\begin{array}{l}\text { Internal fittings (such as light } \\
\text { switches and radiators) }\end{array}$ \\
\hline & & Painting \\
\hline & & $\begin{array}{l}\text { Internal doors, skirting and } \\
\text { architrave }\end{array}$ \\
\hline \multirow[t]{2}{*}{6} & External groundworks & Landscaping \\
\hline & & Driveways \\
\hline \multirow[t]{5}{*}{7} & Occupation and maintenance & Planned maintenance, \\
\hline & & Reactive maintenance \\
\hline & & Alteration \\
\hline & & Renovation \\
\hline & & Extension \\
\hline \multirow[t]{4}{*}{8} & Demolition and redevelopment & Development appraisal \\
\hline & & Demolition \\
\hline & & Sale \\
\hline & & Redevelopment \\
\hline
\end{tabular}

Source: Based upon RIBA guidance. 


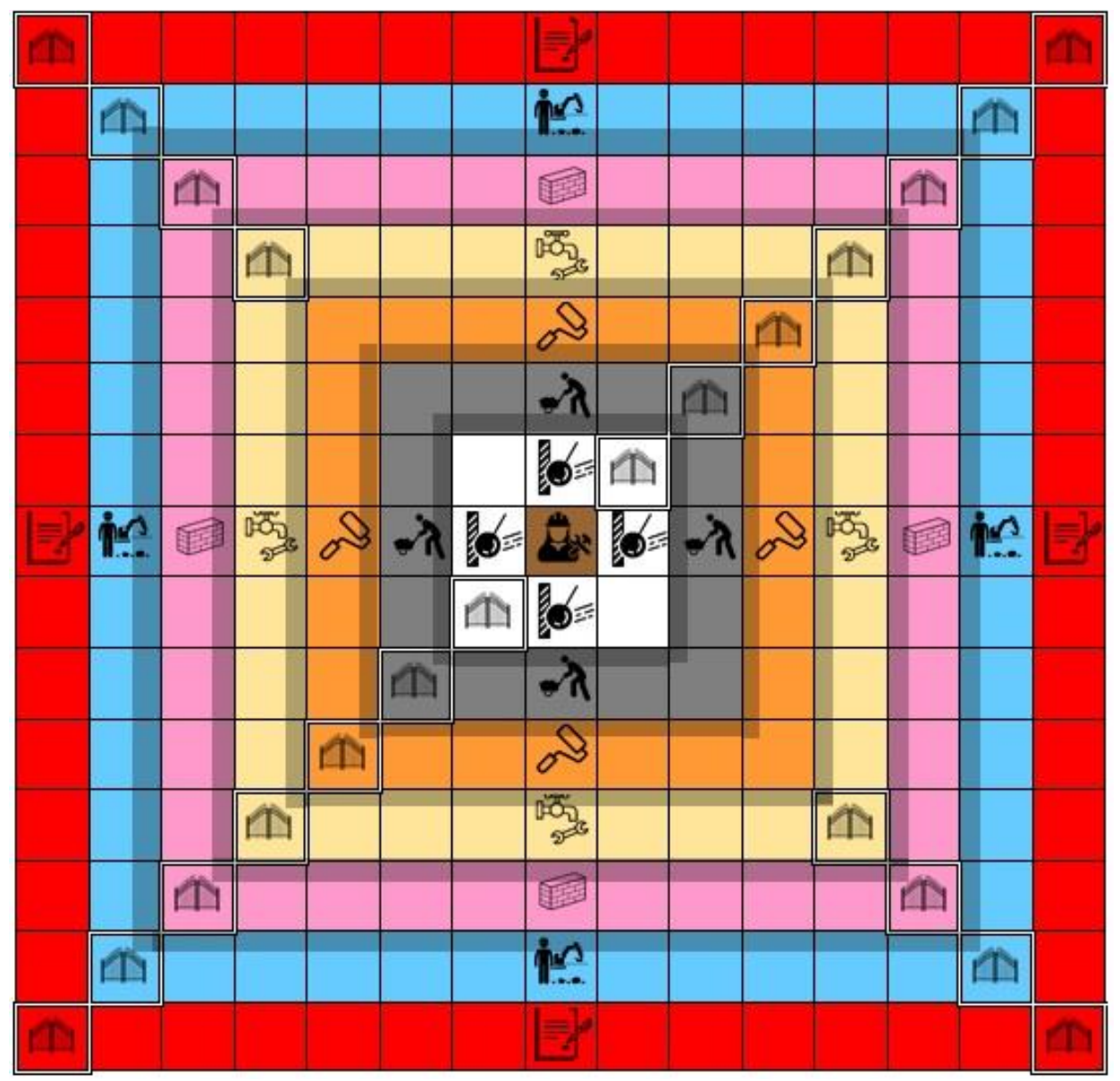

Key:

Tier 3: External envelope
to wall-plate

Figure 3a. Sample gameplay board. 


\section{CATEGORY: GROUNDWORKS}

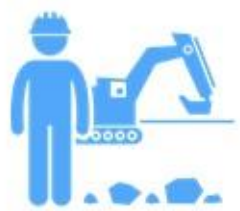

\section{QUESTION?}

On a domestic property, why must the damp proof course (DPC) be placed on engineering quality brick and be at least

$150 \mathrm{~mm}$ above ground level?

\section{ANSWER?}

There are two aspects to this question. First, engineering bricks are impervious to moisture absorption and must always be used in footings - other bricks such as facing bricks would deteriorate rapidly when subjected ground water and freezing temperatures. Second, the DPC is placed on the engineering bricks at $150 \mathrm{~mm}$ above ground level to prevent rain or storm water splashing above the DPC - this would cause internal damp issues for the building's residents.

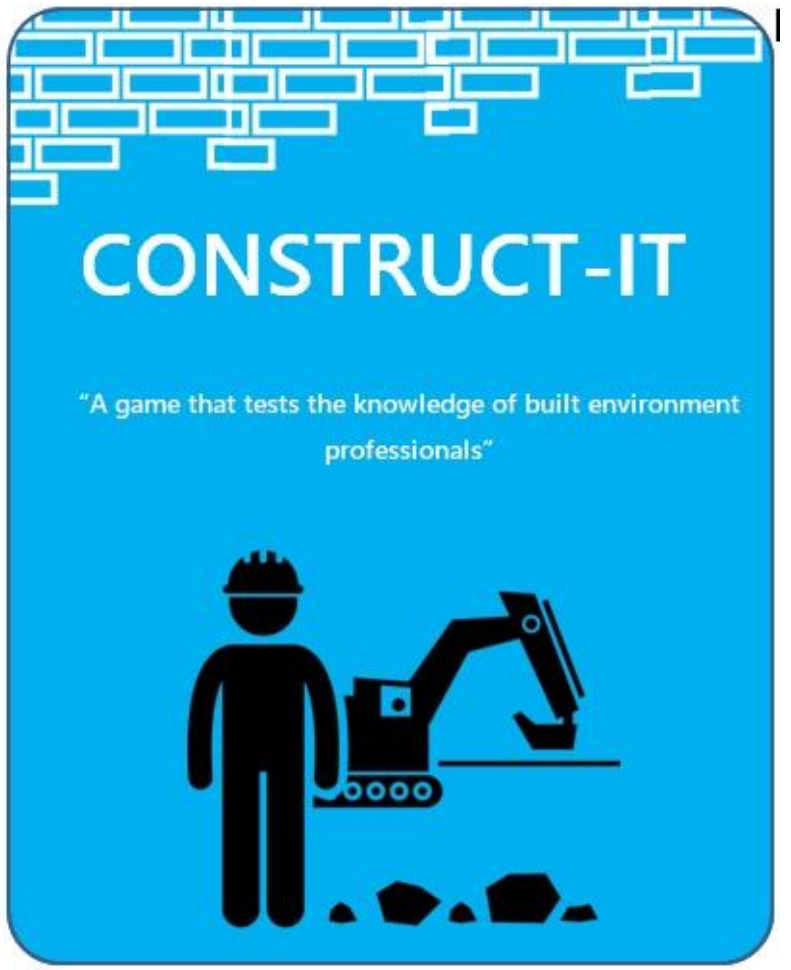

Figure 3b. Sample gameplay card 
Figure 4. An integrated software version of Construct-it.

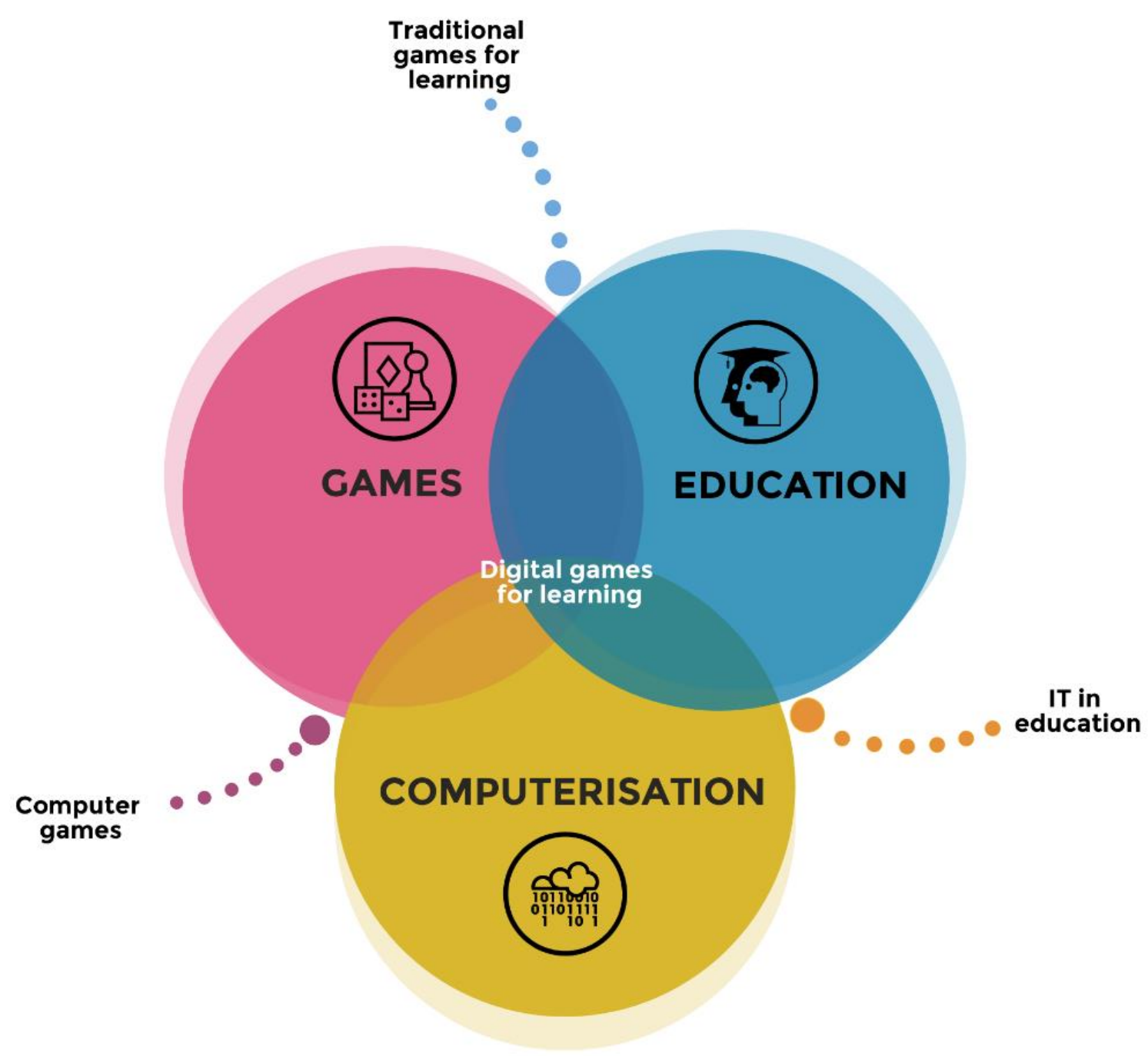

